\title{
Autoregressive moving average models of crown profiles for two California hardwood species
}

\author{
Samantha J. Gill , Gregory S. Biging
}

\begin{abstract}
Time-series Autoregressive Moving Average (ARMA) models were employed to model tree crown profiles for two California hardwood species (blue oak and interior live oak). There are three major components of these models: a polynomial trend, an ARMA model, and unaccounted for variation. The polynomial trend was used to achieve a stationary series. For these crown profiles, the use of a quadratic trend resulted in a stationary series for $60 \%$ of the profiles. A cubic trend was used for another $23 \%$, and a quartic for $7 \%$. It was found that $80 \%$ of the tree crown profiles could be modeled using a first order ARMA model [AR(1), or MA(1)] in conjunction with a polynomial trend and another $10 \%$ as a polynomial trend with white noise. When the coefficients of the ARMA models were statistically significant, the models proved to be both visually and statistically an improvement over the polynomial trend. Using a binary classification scheme it was possible to relate the type of ARMA model needed for a crown profile series to tree size and stand characteristics.
\end{abstract}

\section{Introduction}

Tree crowns are of increasing interest to a growing list of resource professionals including: forest ecologists, wildlife biologists, siliviculturalists, biometeorologists and biometricians. From an ecological perspective tree crowns are the units in which trace gas and energy exchange takes place. Tree crowns also support and orient leaves to allow capture of radiant energy for photosynthesis. Also, birds, insects, and mammals are among its inhabitants. This paper develops tree crown models for hardwood species that potentially can be used in any of these disciplines in support of quantitative predictions of crown form.

Several models of tree crowns have been developed, mostly for conifer species. These models generally fall into three categories, simple Eu- 
clidean shapes, architectural models, or models that take into account the stochastic nature of crowns. For a more complete review of crown modeling than is presented below see Biging and Gill (1997), Gill (1997), or Gill and Biging (2002).

Euclidean models present trees crowns as simple geometric figures attached to a tree bole. Three common models are used: a conic model (Mohren et al., 1984), a parabolic model (Biging and Wensel, 1990; Mitchell, 1975; Mohren et al., 1984), or combinations of two geometric shapes such as a conic top attached to a frustum of a paraboloid (Pretzsch, 1992).

The crown architecture approach is more complicated as it models crown branching patterns (Colin and Houllier, 1992; Maguire et al., 1994), branch orientation (Colin and Houllier, 1992; Honda, 1971) and sometimes branch length (Gavrikov and Karlin, 1992; Ford et al., 1990; Ford and Ford, 1990). This approach provides for a very detailed model, but it requires a wealth of information for parameterization. For a more complete review of the architectural approach refer to Halle et al. (1978), Waller and Steingraeber (1985), Givnish (1986).

Models capturing the stochastic nature of tree crowns include those using fractal geometry (Corona, 1991; Zeide and Gresham, 1991; Zeide and Pfeifer, 1991; Zeide, 1998), stochastic frontier models (Nepal et al., 1996), non-parametric models (Doruska and Mays, 1998) or time-series models (Biging and Gill, 1997; Gill, 1997; Gill and Biging, 2002). Biging and Gill (1997) conducted a pilot study to test the use of time series models for crown profiles. In their study height was equivalent to time and crown radius was the $y$-variable. Then they conducted a much larger study of 219 conifer crown profile series (Gill and Biging, 2002).

This study uses techniques similar to those reported in Gill and Biging (2002), but applied to hardwood species. The crowns of the hardwood species studied herein are inherently more diverse than those of the conifers studied by Biging and Gill (1997) or Gill and Biging (2002). Thus, the main objective of this project was to determine if the autoregressive moving average (ARMA) models employed by Biging and Gill (1997), Gill and
Biging (2002) to conifers are appropriate for hardwood species with highly variable crown forms. A sub-objective was to determine if the order of the ARMA process was related to easily measured tree and stand characteristics.

\section{Data}

Data for this project was collected from the blue oak-foothill (digger or gray) pine habitat type (Verner, 1988). This habitat type is typically diverse in structure, both vertically and horizontally, with a mix of hardwoods, conifers and shrubs. The tree canopy is composed mostly of blue oak (Quercus douglasii) and foothill (digger or gray) pine (Pinus sabiniana Douglas). At lower elevations, blue oaks make up most of the canopy, but at higher elevations, foothill pine generally dominates. Tree associates include interior live oak (Quercus wislizenii), California buckeye (Aesculus californica (Nuttall)), coast live oak (Quercus agrifolia (Nee), and valley oak (Quercus lobata (Nee)) in the Coast Range. The blue oak-foothill pine woodland habitat type occurs along the western foothills of the Sierra Nevada-Cascade range. For this study, the concentration was in the Sierran region and the data collection concentrated on blue oak and interior live oak.

To ensure that trees were sampled from a range of sizes and stand densities, an attempt was made to sample from the following experimental design. Two species (blue oak and interior live oak), three basal area density levels $(<5.74,5.74-11.48,>$ $11.48 \mathrm{~m}^{2} /$ ha $\left(<25,25-50\right.$, and $\left.\left.>50 \mathrm{ft}^{2} / \mathrm{ac}\right)\right)$ and two height classes $(<9.14$ and $>9.14 \mathrm{~m}(<30$ and $>30 \mathrm{ft}$ )) were considered. From each of the 12 species-density-height combinations, an attempt was made to sample $8-10$ trees. Minor deviations from this design occurred because interior live oak often grows in clumps and it was not possible to distinguish the individual tree crowns within these clumps. See Table 1 for the distribution of trees actually sampled.

Every tree in the study was measured for DBH, height, average height-to-crown base, lowest live branch, radius of the crown at the height-to- 


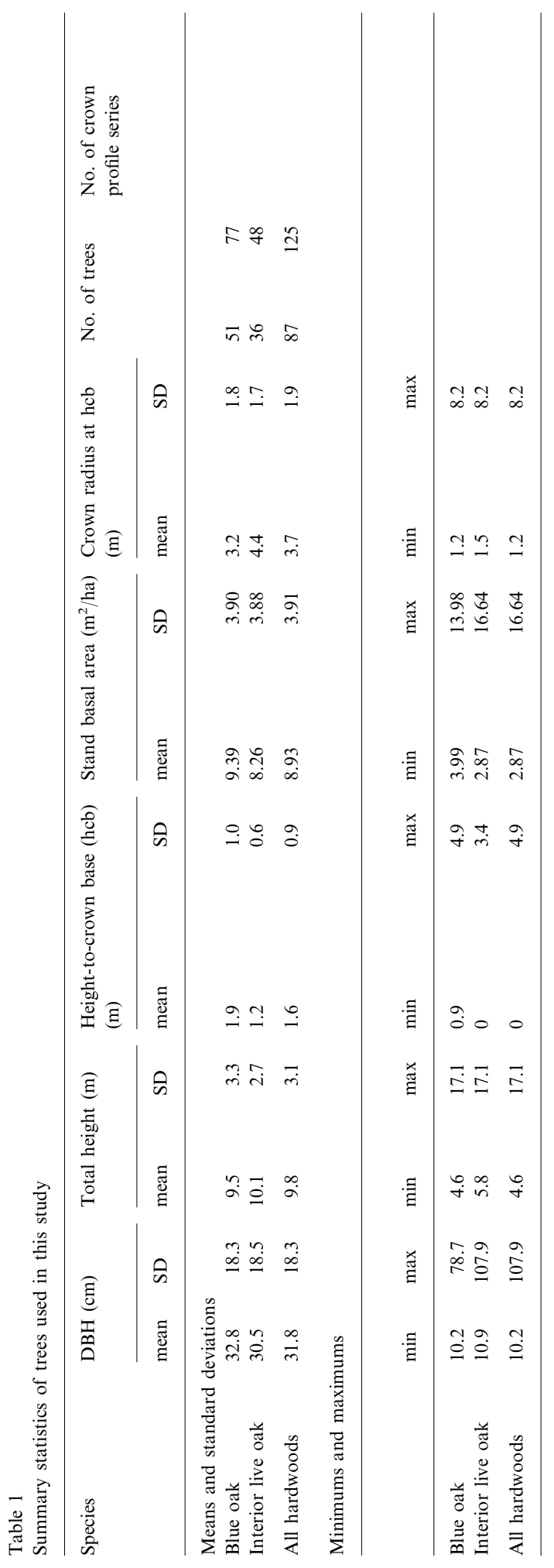


crown base in the direction for which the crown profile was measured and photographed. Stand basal area was calculated by selecting trees using a prism with a basal area factor of $9.2 \mathrm{~m}^{2} / \mathrm{ha}(40$ $\left.\mathrm{ft}^{2} / \mathrm{ac}\right)$. With this method each sample tree represents $9.2 \mathrm{~m}^{2}$ of basal area/ha and so the stand basal area is simply 9.2 multiplied by the number of sample trees. Each sampled tree was also photographed using a $35 \mathrm{~mm}^{\text {Nikon }}{ }^{\mathrm{TM}}$ camera with a 35-210 mm lens ${ }^{1}$. To minimize systematic errors, the lens of the camera was kept within $1-2^{\circ}$ of perpendicular to the bole of the tree at $\mathrm{DBH}$ by placing a carpenter's level on the camera lens.

\section{Methods}

Following the techniques employed by Gill and Biging (2002), the negatives of the photographs were scanned using a Nikon Coolscan Scanner. For these hardwood trees, the average scale of the scanned images was $25 \mathrm{~mm}$ (0.98 in.) per pixel with a standard deviation $\left(S_{x}\right)$ of $12.5 \mathrm{~mm}(0.49$ in.) and a range from $5 \mathrm{~mm}(0.18 \mathrm{in}$.) per pixel to $62 \mathrm{~mm}$ (2.45 in.) per pixel. Using ERDAS (ERDAS, 1991), the crown exterior of each scanned image was screen digitized to acquire $x-y$ coordinate pairs that could be converted to height-radius pairs. By crown exterior we mean that if at a particular height it was possible to locate two distinct edges of the tree crown because of branching patterns the point furthest from the bole of the tree was selected.

A natural cubic spline was fit to the data (Cheney and Kincaid, 1985) to acquire the equidistant measurements needed to facilitate the analysis of time-series data. For these series, the average number of digitized points and interpolated points were $93.4\left(S_{x}=25.1\right)$ and $50.7\left(S_{x}=16.1\right)$, respectively. The average ratio of digitized to interpolated points was $1.9\left(S_{x}=0.5\right)$ with a minimum of 0.9 . There was only one series for which the number of interpolated points was less than the number of digitized points (64 versus 73 ). If the data shifted so erratically that the spline function

\footnotetext{
${ }^{1}$ The lens distortion was less than $5 \%$ in most regions and hence no corrections were made (Gill, 1997).
}

was unable to adjust quickly, linear interpolation was used. In general, we followed the techniques employed by Biging and Gill (1997), Gill and Biging (2002) for analyzing and modeling crown profile data.

A desirable condition for time-series analysis is a stationary series (one with constant mean and variance). The standard technique of differencing a time-series to obtain stationarity does not work with this type of data. Instead a polynomial trend was removed from each series to induce stationarity. For these series a quadratic, cubic or quartic trend was fit to the data using ordinary least squares. The lowest order polynomial producing a stationary series was used for further analysis.

\subsection{ARMA models}

Time-series models were then fit to the residuals of the OLS models. These simple polynomial models were selected for detrending because many models of tree crowns have used similar Euclidean models. In this way, the time-series models explain additional variation over that explained simply by a trend model. As pointed out by Biging and Gill (1997), these time-series models contain three elements: (1) the polynomial trend; (2) the ARMA model; and (3) unexplained variation.

The two step method of first removing the trend to produce a stationary series and then fitting the ARMA model is only one method of fitting non-stationary time-series. Another method is to simultaneously fit the trend and the ARMA model using maximum likelihood estimation (MLE). A disadvantage to using the two-stage approach, which is over come by using the MLE approach, is that the estimates of the standard errors of the trend coefficients may be biased. This bias is significantly reduced with large sample sizes. However, by fitting the model in two stages, one can more easily examine the structure of the ARMA model about the trend. Because we were primarily interested in the structure of the residuals about the trend line, we chose to use the two-stage approach. In addition, we were not concerned with the standard errors of the trend estimates because we did not perform hypothesis tests. Refer to Fuller (1996) for a more thorough 
discussion of the techniques for fitting non-stationary series.

ARMA models were fit to the series of residuals following the methods of Box and Jenkins (1970) as employed by Biging and Gill (1997), Gill and Biging (2002). The equational form of the $\operatorname{ARMA}(p, q)$ model is:

$$
\begin{aligned}
z_{t}= & \phi_{1} z_{t-1}+\phi_{2} z_{t-2}+\cdots+\phi_{p} z_{t-p}+\delta+u_{t} \\
& -\theta_{1} u_{t-1}-\cdots-\theta_{q} u_{t-q},
\end{aligned}
$$

where, $z_{t}=$ crown radius (ft) at height $t$ minus the quadratic, cubic or quartic crown trend (ft) at height $t(t=1, \ldots, T) ; \phi_{i}=$ parameters of the autoregressive factors $(i=1, \ldots, p) ; \theta_{k}=$ parameters of the moving average factors $(k=1, \ldots, q) ; \delta=$ constant; $u_{t}=$ white noise ${ }^{2}$ (Box and Jenkins, 1970).

Two functions, the autocorrelation function (ACF) and the partial autocorrelation function (PACF), were used to assist in the identification stage of the time-series modeling. Because the $\mathrm{ACF}$ and the PACF did not always give a clear indication of the correct ARMA model for the crown profile series in this study, 15 models were estimated for each series (ARMA $(p, q)$, with $(p, q) \in\{(1,0), \quad(2,0), \quad(3,0),(0,1),(0,2),(0,3)$, $(1,1),(2,1),(1,2),(2,2),(3,1),(1,3),(3,2)$, $(2,3),(3,3)\})$. Note that an $\operatorname{ARMA}(p, 0)$ is equivalent to an $\operatorname{AR}(p)$ and an $\operatorname{ARMA}(0, q)$ is equivalent to a $\operatorname{MA}(q)$. To further assist in the identification of the correct ARMA model, a general information criteria, the Bayesian information criteria (BIC) was used. This criteria is a modification of Akaike's information criteria (AIC) (Akaike, 1971, 1974) and penalizes models with more parameters or larger residual sum of squares. For these crown profile series, any model within 5\% (arbitrarily selected) of the lowest (best) BIC was considered acceptable. For a more thorough explanation of these methods, refer to Biging and Gill (1997) or Gill and Biging (2002).

\footnotetext{
${ }^{2}$ White noise is sequence of identically and independently distributed random disturbances with mean zero and variance $\sigma^{2}$.
}

\subsection{Classification of models}

It is informative to know if the type of ARMA model that is best for each series can be predicted from knowledge of tree species, size or stand characteristics. We envision that it will be possible to simulate the profiles of all trees in a forest stand if we know which model to apply and then can predict the ARMA coefficients for each tree's profile. This later step will be the subject of future papers.

We detrended the series, identified and estimated the coefficients of the ARMA model for each series as described under ARMA models above. Then we employed a classification scheme to determine if the appropriate order of the ARMA model was related to tree species, size, or stand characteristics. To complete this task, a binary classification scheme, Classification and Regression Trees (CART) (Breiman et al., 1984), was used. For the purpose of classification, one and only one ARMA model was identified for each series. For this classification scheme, only the first order $[\mathrm{AR}(1)$ and $\mathrm{MA}(1)]$ and the $\mathrm{AR}(0)$ (trend plus white noise) were used for stationary series. We chose to use only first order models and $\operatorname{AR}(0)$ because they accounted for a majority of the models (see Section 4) and because they are the most parsimonious of the models. In addition, all series for which the removal of up to a fourth order polynomial did not produce a stationary series were identified as 'non-stationary'. Since the AR(1) model requires the measurement (or estimation) of the crown radius at the height-tocrown base and the MA(1) does not, the MA(1) model was the preferred model. In this way any series for which the MA(1) model was appropriate (BIC within $5 \%$ of best with significant coefficients) was identified as an MA(1). This was true even if both the $\mathrm{MA}(1)$ and the $\mathrm{AR}(1)$ were appropriate. The AR(1) model was the second choice. So any series for which an AR(1) coefficients were significant and the BIC was within 5\% of the best, but for which the MA(1) was not within $5 \%$ of the best was assigned to the AR(1). Any series which could not be modeled as an MA(1) or an AR(1) was assigned to an AR(0) model if the removal of the trend produced a 
stationary series and to a 'non-stationary' class if the removal of a trend did not produce a stationary series.

After each series was identified as one of the models, the CART analysis was performed. CART was used instead of discriminant analysis for two primary reasons, the ease of including categorical variables, such as species, and because the assumption of multivariate normality needed for discriminant analysis could not be met with our data. CART does not require normality of observations.

Because of limited data, it was not possible to reserve some of the data for testing the classification trees. Instead, a cross-validation technique was used to determine an appropriate size for the classification tree. Using this technique, different classification trees were compared and large trees were pruned to an appropriate size.

\section{Results}

The first step in the analysis was to detrend the series. A quadratic trend was sufficient for $60 \%$ of the series, for $23 \%$ of the series a cubic trend was used and for another 7\% a quartic trend was used. The other $10 \%$, which would need some other trend to produce a stationary series, were assigned a model type of 'non-stationary' and not modeled further. The ARMA models were then fit to the residuals around the trend. If the time-series models tested were statistically significant then they were a de facto improvement over using simple geometric forms (quadratic, cubic, or quartic trend).

Models for which the BIC was within $5 \%$ of the smallest BIC and for which the time-series coefficients were significant were judged to be nearly optimal and thus appropriate for modeling. It was found that 86 of 125 hardwood series could be modeled as an AR(1) and that 29 could be modeled as an MA(1) (see Table 2).

In addition to being statistically an improvement over the simple Euclidean models, these time-series models were visually an improvement when used to predict tree crown profiles. As examples of these simulations refer to Fig. 1 for a simulated AR(1), Fig. 2 for a simulated MA(1) and to Fig. 3 for a simulated AR(0) model. In their models of conifer crown profiles, Biging and Gill (1997), Gill and Biging (2002) found that the AR(1) and MA(1) were visually similar and in this study we found that also holds for the hardwood crown profiles (see Fig. 4). It can be seen, however, that differences in prediction of crown ra-

Table 2

Model types with smallest BIC-hardwoods

\begin{tabular}{lcc}
\hline Model type & $\begin{array}{l}\text { No. of series where this } \\
\text { model type has the smallest BIC }\end{array}$ & $\begin{array}{l}\text { No. of series where this model has smallest } \\
\text { BIC or is within 5\% of smallest BIC }\end{array}$ \\
\hline AR(0) & 7 & 7 \\
AR(1) & 67 & $86^{\mathrm{a}}$ \\
AR(2) & 9 & 20 \\
AR(3) & 20 & 3 \\
MA(1) & 1 & 29 \\
MA(2) & 0 & 8 \\
MA(3) & 5 & 3 \\
ARMA(1, & 0 & 19 \\
ARMA $(2,1)$ & 2 & 1 \\
ARMA(1, 2) & 1 & 7 \\
ARMA(2, & 0 & 2 \\
ARMA $(3,1)$ & 1 & 2 \\
ARMA $(1,3)$ & 125 & \\
Total & &
\end{tabular}

${ }^{\text {a }}$ For 15 of these series the MA(1) model was also within $5 \%$ of the lowest BIC. 

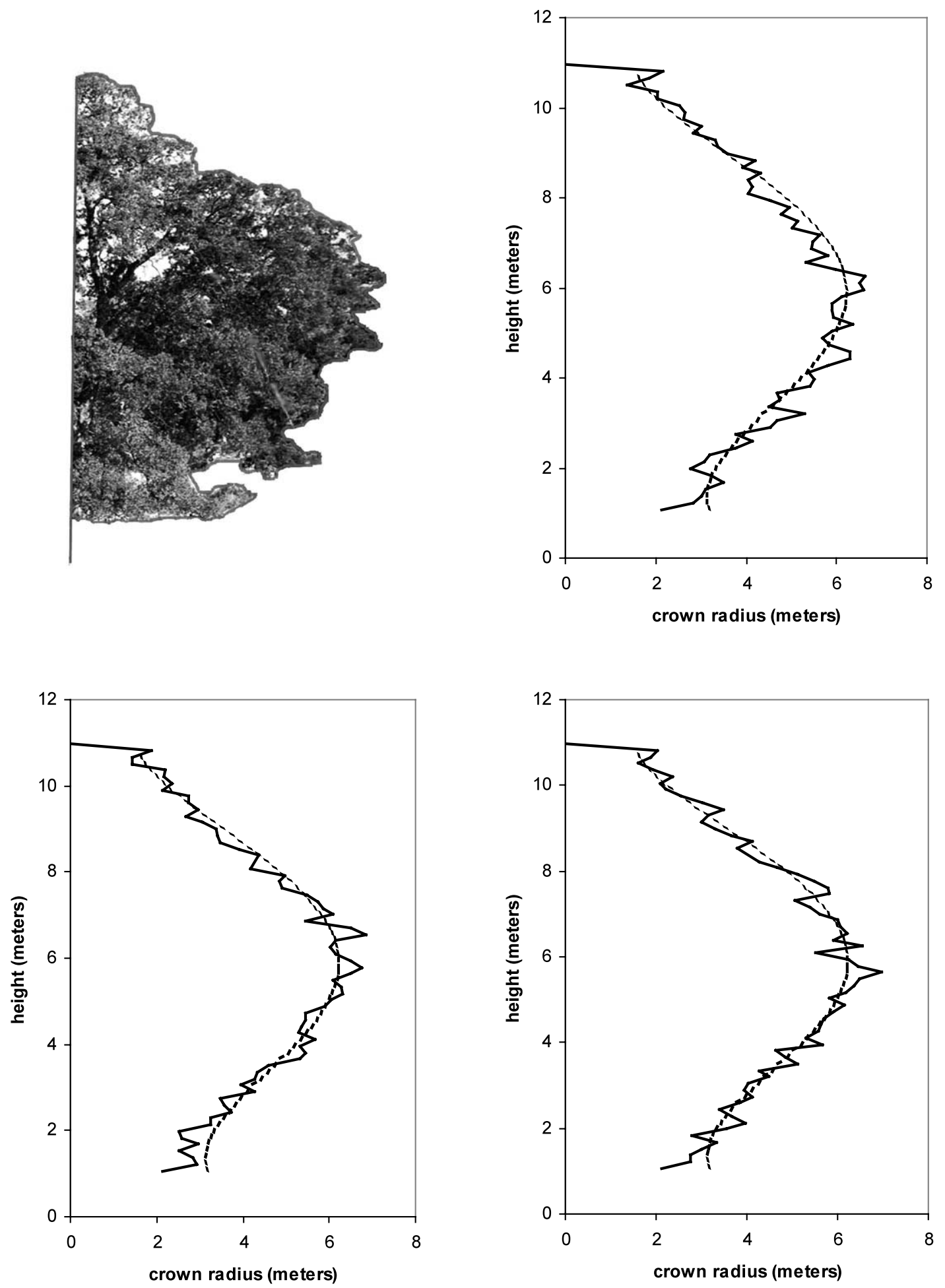

Fig. 1. Simulations using an AR(1) process $\left[\operatorname{crrad}_{t}=0.356 \mathrm{crrad}_{t-1}+u_{t}+\left(4.607-2.419 \mathrm{ht}_{t}+1.191 \mathrm{ht}_{t}^{2}-0.164 \mathrm{ht}_{t}^{3}+0.007 \mathrm{ht}_{t}^{4}\right)\right.$; where $\operatorname{crrad}_{t}=$ crown radius, $\mathrm{ht}_{t}=$ height along crown of tree, $u=$ white noise series with variance 0.101$]$ for a blue oak tree (42.4 $\mathrm{cm}$ in DBH and $11.0 \mathrm{~m}$ tall). The dashed line is the trend (quartic) used in simulation. The graph in the upper left is a photo of the tree crown and the remaining three are simulations with the trend. 

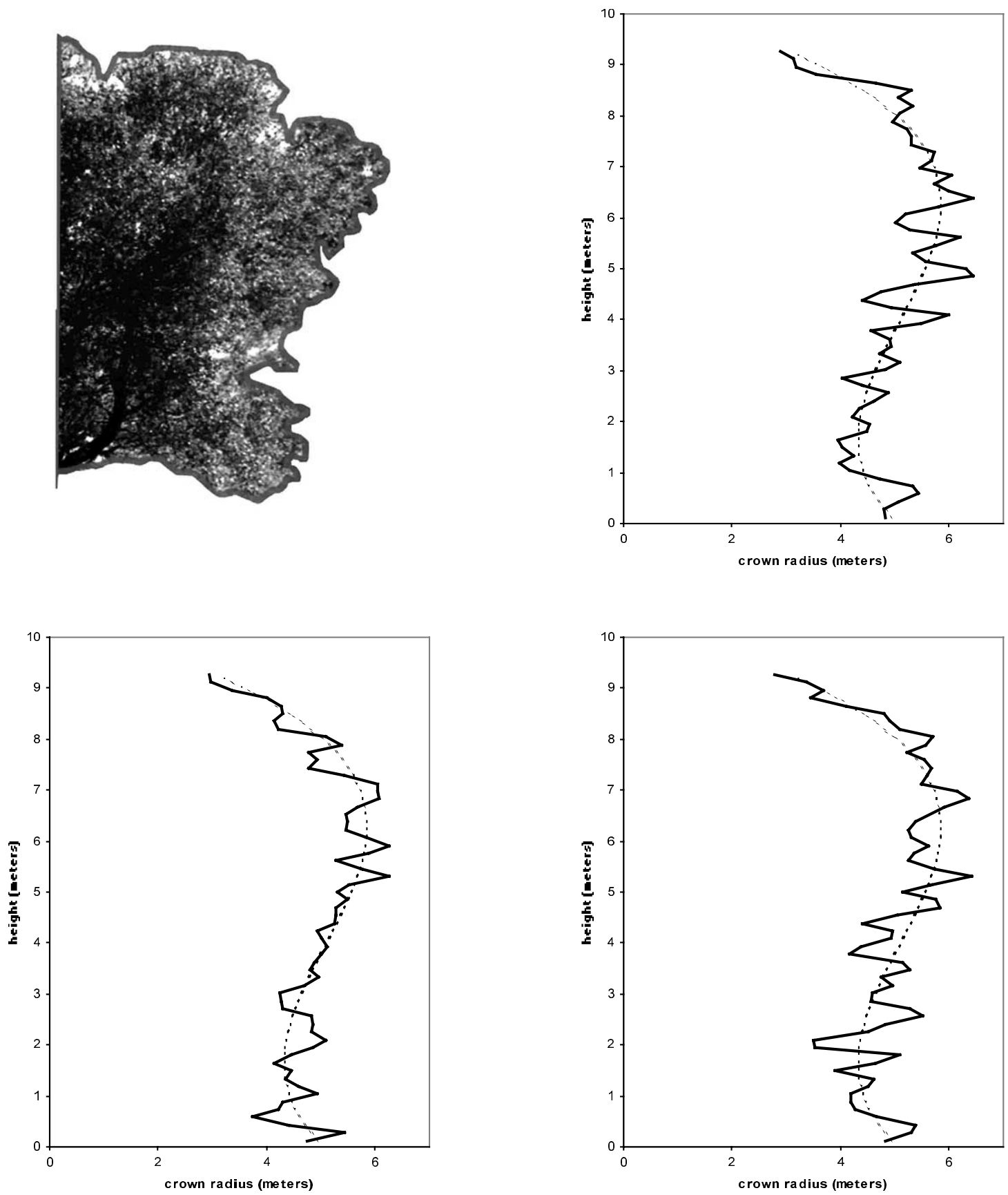

Fig. 2. Simulations using an MA(1) process $\left[\operatorname{crrad}_{t}=-0.904 u_{t-1}+u_{t}+\left(5.040-0.963 \mathrm{ht}_{t}+0.367 \mathrm{ht}_{t}^{2}-0.031 \mathrm{ht}_{t}^{3}\right)\right.$; $\mathrm{where} \mathrm{crrad}_{t}=$ crown radius, $\mathrm{ht}_{t}=$ height along crown of tree, $u=$ white noise series with variance 0.096 ] for a interior live oak tree $(76.2 \mathrm{~cm}$ in DBH and $9.75 \mathrm{~m}$ tall). The dashed line is the trend (cubic) used in simulation. The graph in the upper left is a photo of the tree crown and the remaining three are simulations with the trend. 

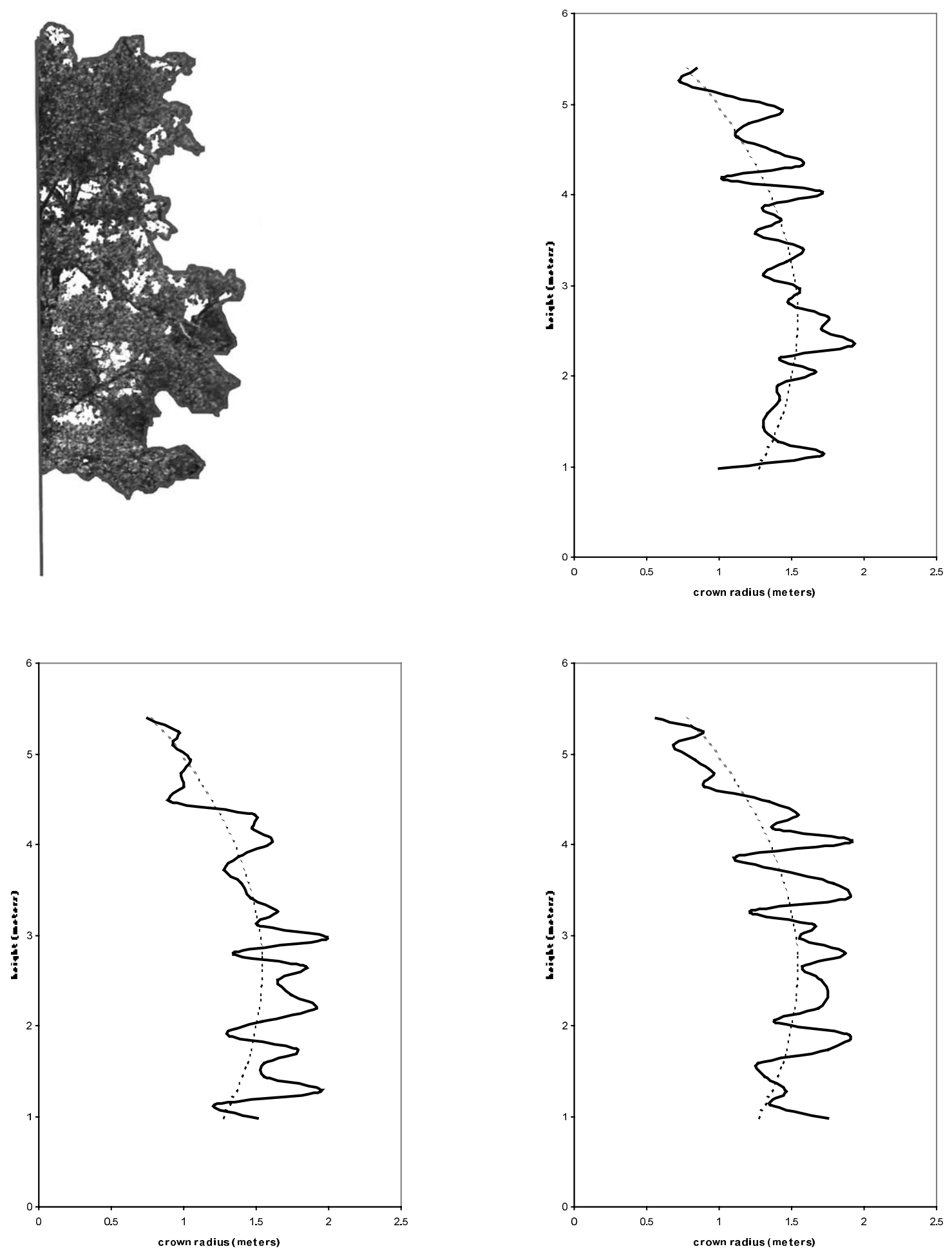

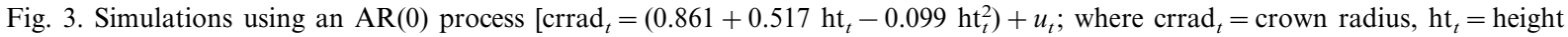
along crown of tree, $u=$ white noise series with variance 0.059 ] for a blue oak tree $(12.2 \mathrm{~cm}$ in DBH and $5.5 \mathrm{~m}$ tall). The dashed line is the trend (quadratic) used in simulation. The graph in the upper left is a photo of the tree crown and the remaining three are simulations with the trend. 

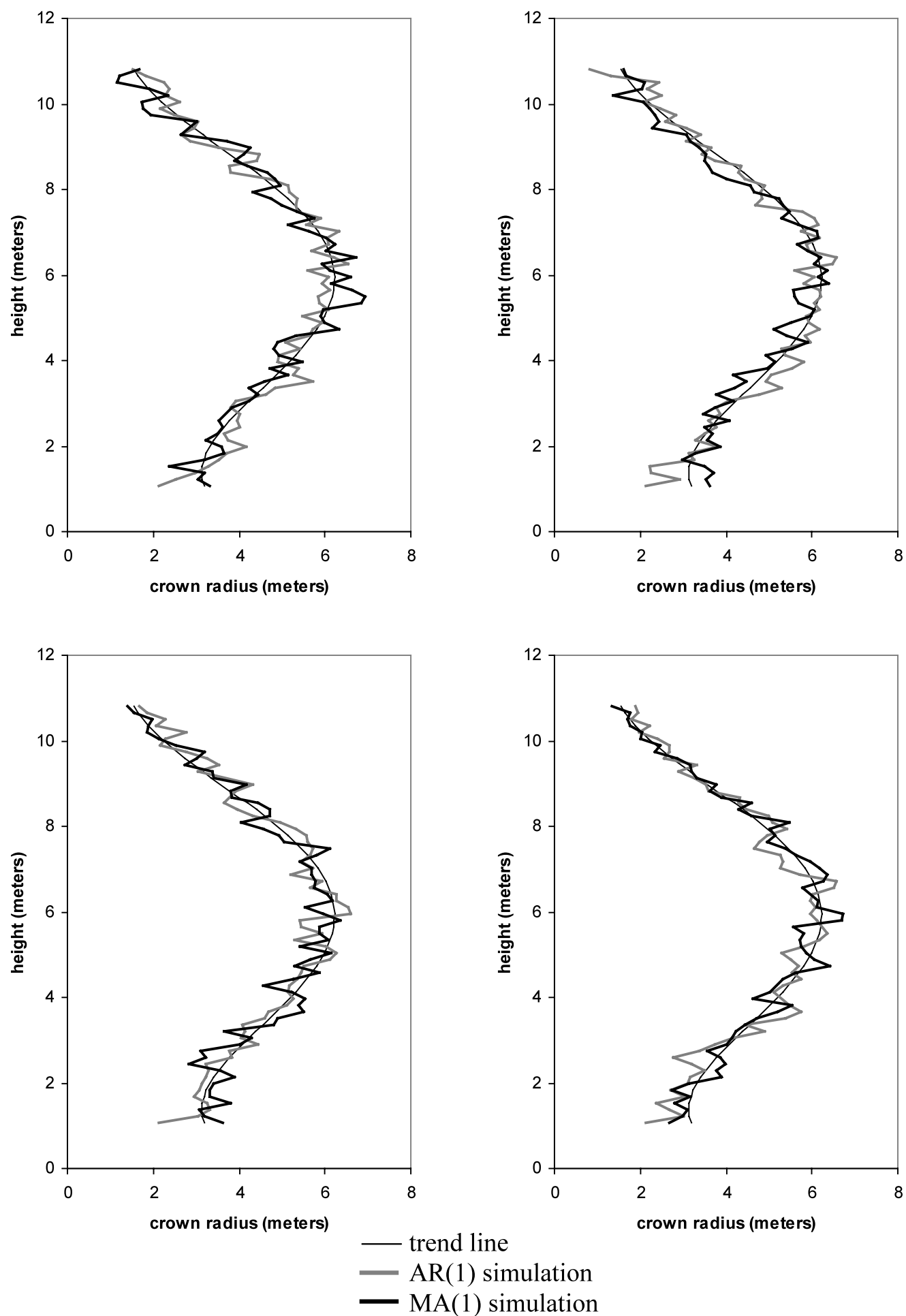

Fig. 4. Simulations using AR(1) and an MA(1) processes for the same tree. Also plotted is the trend line. Note that this is the same tree as in Fig. 1. The equation for the AR(1) simulation is $\operatorname{crrad}_{t}=0.356 \mathrm{crrad}_{t-1}+u_{t}+\left(4.607-2.419 \mathrm{ht}_{t}+1.191 \mathrm{ht}_{t}^{2}-0.164\right.$ $\mathrm{ht}_{t}^{3}+0.007 \mathrm{ht}_{t}^{4}$ ); and for the MA(1) is $\operatorname{crrad}_{t}=-0.289 u_{t-1}+u_{t}+\left(4.607-2.419 \mathrm{ht}_{t}+1.191 \mathrm{ht}_{t}^{2}-0.164 \mathrm{ht}_{t}^{3}+0.007 \mathrm{ht}_{t}^{4}\right)$; where $\operatorname{crrad}_{t}=$ crown radius, $\mathrm{ht}_{t}=$ height along crown of tree, $u=$ white noise series with variance of 0.101 and 0.104 for the AR(1) process and the MA(1) process, respectively. 
dius at the crown base occur since the AR(1) uses this value for initialization whereas the MA(1) does not.

\subsection{Classification of ARMA models}

In the development of a CART it was necessary to associate each series with one and only one ARMA model. This identification was done by using only first order models (AR(1) and MA(1)) along with the $\mathrm{AR}(0)$ model. Series were assigned to these models only if the BIC was within $5 \%$ of the smallest and the coefficients of the model were significant. For the number of series in each class, see Table 3. From this table, it can be seen that roughly $80 \%(100 / 125)$ could be modeled using first order ARMA models.

The classification tree (from CART) to determine which type of model should be used for a given tree is shown in Fig. 5. When interpreting this figure, if the statement is true follow the branch to the left and if it is false follow the branch to the right. This tree has nine terminal nodes, uses DBH $(\mathrm{cm})$, height $(\mathrm{m})$, crown radius (m) at the height-to-crown base, and stand basal area $\left(\mathrm{m}^{2} / \mathrm{ha}\right)$ for classification. This tree has a misclassification rate of $37.6 \%$ (see Table 4). It is interesting to note that species was not one of the variates used in the classification. For this classification size measures of the tree (diameter, height and crown radius) were the most important indicators of which model should be used for specific crown profile series.

The misclassification rate of $37.6 \%$ indicates that slightly over one-third of time, the wrong model type will be selected for simulation purposes. This rate, while high, is on par with misclassification rates reported by Gill and Biging (2002) for conifer tree crown profiles. When trees are misclassified as to type of ARMA model it could result in less accurate crown profiles for a given tree. But qualitatively, an AR(1) simulation and an $\mathrm{MA}(1)$ simulation result in similar tree crown profiles (see Fig. 4). This is not surprising considering an AR(1) model can be approximated with a relatively small order MA process and vice versa. Approximately $47 \%$ of the misclassified series involve the misclassification between $\mathrm{AR}(1)$
Table 3

Table of 'best' model for the crown profiles

\begin{tabular}{ll}
\hline Model & Number of times series judged best \\
\hline AR(0) & $13(10 \%)$ \\
MA(1) & $29(23 \%)$ \\
AR(1) & $71(57 \%)$ \\
Other & $12(10 \%)$ \\
Total & 125
\end{tabular}

a Only first order ARMA models and the white noise model were used in this classification.

${ }^{\mathrm{b}}$ Removal of a quadratic, cubic, or quartic trend was not sufficient to achieve a stationary series.

and MA(1) models (refer to the confusion matrix in Table 4). Hence the effective misclassification rate is considerably less than reported and involves primarily the misclassification of $\mathrm{AR}(0)$ versus $\mathrm{AR}(1)$ or $\mathrm{MA}(1)$.

\section{Conclusion}

This project demonstrated that the methods developed by Biging and Gill (1997), Gill and Biging (2002) can also be applied to hardwood crown profiles. For these hardwood crown profiles it was found that $80 \%$ could be modeled using first order ARMA models, and that another 10\% could be modeled as a polynomial trend plus an AR(0) model. All of these time-series models were found to be visually an improvement over simple geometric forms. Since the ARMA coefficients were significant, the time-series models were shown to be statistically an improvement over using simple Euclidean geometric forms.

These results are similar to those found by Gill and Biging (2002) for conifer crown profiles. For conifers their results indicated that ca. $70 \%$ of the crowns could be modeled as first order ARMA models with an additional $25 \%$ as a trend plus an AR(0) model.

In both the hardwoods reported here and the conifers studied by Gill and Biging (2002), the model that was most commonly judged as best was the AR(1) model. However, more hardwood 


\section{Legend}

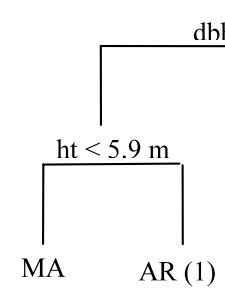

dhh $<19.4 \mathrm{~cm}$
Tree and Stand variables

Dbh diameter at breast height $(\mathrm{cm})$

ht total tree height (m)

cr crown radius $(\mathrm{m})$

ba stand basal area $\left(\mathrm{m}^{2} / \mathrm{ha}\right)$
ARMA model

$\operatorname{AR}(0)$ white noise model AR(1) $1^{\text {st }}$ order autoregrssive

$\operatorname{MA}(1) 1^{\text {st }}$ order moving av.

Note: If the statement is true, branch to the left.

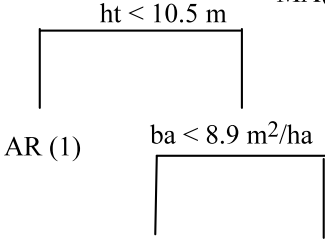

AR (1)

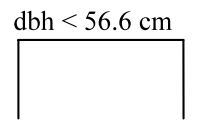

AR (1)

$\mathrm{AR}(0)$

Fig. 5. CART classification scheme for the determination of which ARMA model to use on a specific tree.

Table 4

Confusion matrix for the CART analysis of the ARMA models

\begin{tabular}{|c|c|c|c|c|c|c|}
\hline \multirow{2}{*}{$\frac{\text { Actual }}{\text { Model }}$} & \multicolumn{4}{|c|}{ Predicted Model } & \multirow[t]{2}{*}{ Row totals } & \multirow[t]{2}{*}{ User’s Acc.\% } \\
\hline & $\mathrm{AR}(0)$ & $\mathrm{AR}(1)$ & MA(1) & Non-stationary & & \\
\hline $\mathrm{AR}(0)$ & 3 & 6 & 4 & 0 & 13 & 23.1 \\
\hline $\mathrm{AR}(1)$ & 1 & 61 & 9 & 0 & 71 & 85.9 \\
\hline MA(1) & 2 & 13 & 14 & 0 & 29 & 48.3 \\
\hline Non-stationary & 0 & 12 & 0 & 0 & 12 & 0 \\
\hline Total & 6 & 92 & 27 & 0 & 125 & \\
\hline Producer’s acc. $\%$ & 50.0 & 66.3 & 51.9 & 0 & & Overall acc. $\% 62.4$ \\
\hline
\end{tabular}

trees were modeled as a trend plus an $\operatorname{AR}(0)$ than were the conifer crowns. Another difference between the results of the hardwoods and conifers is that Gill and Biging (2002) were able to achieve stationarity for the conifer crowns by removing only a quadratic trend for $95 \%$ of their crown series with the additional $5 \%$ not being modeled. In this study, the quadratic trend was only sufficient for $60 \%$ of the series, with another $23 \%$ required a cubic trend, and $7 \%$ a quartic trend.
For these hardwood crown profiles, there were $10 \%$ for which a polynomial model did not provide a stationary series compared to only $5 \%$ of the conifers in the previous conifer study. While we anticipated that ARMA models would be appropriate for hardwood profiles it is somewhat surprising that a slightly higher percentage of hardwood than conifer crowns were adequately represented by low order ARMA models. Because of the highly variable form of 
hardwoods we anticipated this result to be reversed.

Using a binary classification technique, it was possible to develop reasonably accurate classification rules for when each type of model [MA(1), AR(1), or AR(0)] should be used. This classification was based solely on tree and stand characteristics, thus indicating that there is a relationship between tree characteristics and the type of first order ARMA model needed to model a crown profile.

Although, visually and statistically an improvement over simply Euclidean models, the models developed in this study were for individual trees and much data is needed to parameterize them. In future studies, we will predict the trend coefficients and the coefficients of the ARMA models from commonly measured tree and stand variates. In this way tree crown profiles can be predicted from inventory data and used in other applications such as 3-D stand visualization programs (Burkhart, 1992; McGaughey, 1998; Nagel, 1997; Pretzsch, 1993). This type of structural information will also be useful to forest managers and silviculturists and may be used in conjunction with forest aesthetics and wildlife habitat management. Another possible application is in modeling the shading of hardwood trees in urban settings.

\section{References}

Akaike, H. 1971. Information theory and an extension of the maximum likelihood principle. In: Petrov, B.N., Csaki, F. (Eds.), Research Memorandum No. 46, Institute of Statistical Mathematics Tokyo, Published in 2nd International Symposium On Information Theory, Akademiai Kiade, Budapest (1973), pp. 267-281.

Akaike, H., 1974. A new look at the statistical model identification. Institute of Electrical and Electronic Engineers Transactions on Automatic Control AC-19, pp. 716-722.

Biging, G.S., Gill, S.J., 1997. Stochastic models for conifer tree crown profiles. Forest Science 43 (1), 25-34.

Biging, G.S., Wensel, L.C., 1990. Estimation of crown form for six conifer species of northern California. Canadian Journal of Forest Research 20 (20), 1137-1142.

Box, G.E.P., Jenkins, G.M., 1970. Time-series Analysis: Forecasting and Control. Holder-Day, San Francisco, p. 553.

Breiman, L., Friedman, J.H., Olshen, R.A., Stone, C.J. 1984. Classification and Regression Trees. Monterey, Wadsworth and Brooks/Cole Advanced Books and Software, 358 pp.
Burkhart, H.E., 1992. Scientific visualization for the study and use of forest stand simulators. Landscape and Urban Planning 21 (4), 317-318.

Cheney, W., Kincaid, D., 1985. Numerical mathematics and computing. In: Second Monterey. Brooks/Cole Publishing, p. 562 .

Colin, F., Houllier, F., 1992. Branchiness of Norway spruce in northeastern France: predicting the main crown characteristics from usual tree measurements. Anneles Des Sciences Forestieres 49(5), 511-538.

Corona, P., 1991. Studying tree crown architecture by fractal analysis. Italia Forestale E Montana 46 (4), 291-307.

Doruska, P.F., Mays, J.E., 1998. Crown profile modeling of loblolly pine by nonparametric regression analysis. Forest Science 4 (3), 445-453.

ERDAS, 1991. ERDAS Field Guide, Atlanta.

Ford, E.D., Avery, A., Ford, R., 1990. Simulation of branch growth in the Pinaceae: interactions of morphology, phenology, foliage productivity, and the requirement for structural support, on the export of carbon. Journal of Theoretical Biology 146, 15-36.

Ford, R., Ford, E.D., 1990. Structure and basic equations of a simulator for branch growth in the Pinaceae. Journal of Theoretical Biology 146, 1-13.

Fuller, W.A., 1996. Introduction to Statistical Time Series, 2nd ed. John Wiley \& Sons, New York.

Gavrikov, V.L., Karlin, I.V., 1992. A dynamic model of tree terminal growth. Canadian Journal of Forest Research 23 (2), 326-329.

Gill, S.J., 1997. Stochastic Models of Tree Crown Profiles. Ph.D. Thesis, Environmental Science Policy and Management, Berkeley, CA, University of CA, 185 p.

Gill, Samantha J., Biging, G.S., 2002. Autoregressive moving average (ARMA) models of conifer crown profiles. Accepted in Journal of Agricultural, Biological and Environmental Statistics.

Givnish, T.J. (Ed.), 1986. On the Economy of Plant Form and Function. Cambridge University Press, Cambridge.

Halle, F., Oldeman, R.A.A., Tomlinson, P.B., 1978. Tropical Trees and Forests. Springer-Verlag, Berlin.

Honda, H., 1971. Description of the form of trees by the parameters of the tree like body: effects of the branching angle and the branch length in the shape of the tree like body. Journal of Theoretical Biology 31, 331-338.

Maguire, D.A., Moeur, M., Bennett, W.S., 1994. Models for describing basal diameter and vertical distribution of primary branches in young Douglas-fir. For. Ecol. Manage. 63, 23-55.

McGaughey, R.J., 1998. Techniques for visualizing the appearance of forestry operations. Journal of Forestry 96 (6), 9-14.

Mitchell, K.J., 1975. Dynamics and simulated yield of Douglas-fir. Forest Science Monograph 17 (4), 37.

Mohren, G.M.J., Gerwen, C.P.V., Spitters, C.J.T., 1984. Simulation of primary production in even-aged stands of Douglas-fir. For. Ecol. Manage. 9, 27-49. 
Nagel, J., 1997. BWIN: program for stand analysis and prognosis. User's Manual for Version 3.0, Abteilung Waldwahstum, Niedersächsischen Forstlichen Versuchsanstalt, 42 pp.

Nepal, S.K., Somers, G.L., Caudill, S.H., 1996. A stochastic frontier model for fitting tree crown shape in Loblolly pine (Pinus taeda L.). Journal of Agricultural, Biological and Environmental Statistics 1 (3), 336-353.

Pretzsch, H., 1992. Modellierung der Kronenkondurrenz von Fichte und Buche in Rein- und Mischbeständen. Allgemeine Forest- und Jagdzeitung 163 (11-12), 203-213.

Pretzsch, H., 1993. Analyse und Reproduktion räumlicher Bestandesstrukturen. Versuche mit dem Strukturgenerator STRUGEN. Schriften aus der Forstlichen Fakultät Göttingen und der Niedersächsischen Forstlichen Versuchsanstalt, Band 114, Sauerländer's Verlag, 87S.

Verner, J., 1988. Blue Oak-Digger Pine Habitat type. A Guide to Wildlife Habitats of California. In: Mayer, K.E., J. William F. Laudenslayer (Eds.), Sacramento, pp. 46-48.

Waller, D.M., Steingraeber, D.A., 1985. Branching and modular growth: theoretical models and empirical patterns. In: Jackson, J.B.C., LeoW, B., Cook, R.E. (Eds.), Population Biology and Evolution of Clonal Organisms. Yale University Press, New Haven, pp. 225-257.

Zeide, B., 1998. Fractal analysis of foliage distribution in loblolly pine crowns. Canadian Journal of Forest Research $28,106-114$.

Zeide, B., Gresham, C.A., 1991. Fractal dimensions of tree crowns in three loblolly pine plantations of coastal South Carolina. Canadian Journal of Forest Research 21 (8), $1208-1212$.

Zeide, B., Pfeifer, P., 1991. A method for estimation of fractal dimension of tree crowns. Forest Science 37 (5), 12531265 . 